\title{
Improvement of Demagnetization by Rotor Structure of IPMSM with Dy-free Rare-Earth Magnet
}

\author{
Keigo Imamura*, Masayuki Sanada*, Shigeo Morimoto* and Yukinori Inoue*
}

\begin{abstract}
Permanent magnet (PM) motors that employ rare-earth magnets containing dysprosium (Dy) are used in electric and hybrid electric vehicles. However, it is desirable to reduce the amount of Dy used since it is expensive. This study investigates the rotor structure of a PM synchronous motor with a Dy-free rare-earth magnet. Flux barrier shapes and PM thicknesses that enhance the irreversible demagnetization are investigated. In addition, a rotor structure that improves the irreversible demagnetization is proposed. We demonstrate that the proposed rotor structure without Dy improves the irreversible demagnetization.
\end{abstract}

Keywords: Demagnetization, Dysprosium, IPMSM, Rare-Earth Magnet

\section{Introduction}

Permanent magnet (PM) motors that employ rare-earth magnets containing dysprosium (Dy) are currently used in electric and hybrid electric vehicles. Such PM motors have high efficiencies, high powers, and high power densities. In these applications, the magnetomotive force of the armature reaction that demagnetizes the magnet in the rotor is large because a large current is applied to the motor to obtain a high torque and a high power. Because of this force, the magnet is affected by the demagnetization field. Consequently, the operating point of the magnet moves along its demagnetization curve. If the magnetomotive force of the armature reaction is sufficiently large, the operating point will pass a knee point that appears at high temperatures in the demagnetization curves of rare-earth PMs. Consequently, the PM is irreversibly demagnetized [1]-[4], which causes serious problem of torque decrease. Therefore, in these applications, Dy is added to rare-earth PMs to increase the magnetic coercive force. However, Dy is very rare and expensive. For these reasons, it highly desirable to reduce the amount of Dy used.

Demagnetization of interior permanent magnet synchronous motors (IPMSMs) can be suppressed by the following method. Flux from the stator winding crosses a small part of the reluctance. Thus, reducing the reluctance of the flux barrier in the rotor is expected to reduce the effect of the magnetomotive force on the magnet. In

\footnotetext{
* Dept of Electrical and Information Systems, Graduate School of Engineering, Osaka Prefecture University, Japan. (ss106003@edu.osakafu-u.ac.jp; sanada@eis.osakafu-u.ac.jp; morimoto@eis.osakafu-u.ac.jp; inoue@eis.osakafu-u.ac.jp)
}

Received 30 March 2013 ; Accepted 22 May 2013 addition, increasing the reluctance of the magnet is anticipated to improve the demagnetization. This study investigates the rotor structure of an IPMSM with a Dy-free rare-earth magnet. Flux barrier shapes and magnet thicknesses that suppress irreversible demagnetization are investigated. In addition, we investigate how the flux barrier shape and the magnet thickness affect the torque performance [5]-[7]. Finally, a rotor structure that suppresses irreversible demagnetization is presented.

\section{Basic Model and Evaluation Method for Demagnetization Rate}

\subsection{Basic model and specifications}

Fig. 1 shows the basic model used in this study, while Table 1 lists its specifications. It has 24 slots and four poles. Distributed winding is used in the stator. The rated current density is $7.5 \mathrm{~A} / \mathrm{mm}^{2}$, which corresponds to a current of $5.37 \mathrm{~A}$. The operating temperature of the magnets is assumed to be $110^{\circ} \mathrm{C}$.

\subsection{Evaluation Method for Demagnetization Rate}

In this study, N32EZ, which contains Dy, and N52, which is Dy free, are used in the rotor. Fig. 2 shows the demagnetization curves of $\mathrm{N} 32 \mathrm{EZ}$ and $\mathrm{N} 52$ at $110^{\circ} \mathrm{C}$. In this study, the irreversible demagnetization was determined as follows. The magnet is judged to have suffered irreversible demagnetization when the flux density of the magnet is less than that of the knee in the curve. To determine the demagnetization, the magnetic flux density of 
the magnet was calculated by the 2-D fenite element method (FEM). The rate of irreversible demagnetization was calculated from the magnet amount of irreversible demagnetization against the total magnet amount [2]-[3]. This rate is called the demagnetization rate. For N52, the knee point appears at flux density of $0.8 \mathrm{~T}$. Thus, the flux density for irreversible demagnetization was $0.8 \mathrm{~T}$ at $110^{\circ} \mathrm{C}$. We assumed the most severe conditions by setting the current phase angle $\beta$ to $90^{\circ}(\beta$ is defined as the leading electrical angle relative to the $q$ axis) and the current density to $22.5 \mathrm{~A} / \mathrm{mm}^{2}$, which is three times the rated current density.N52 at 15 and $22.5 \mathrm{~A} / \mathrm{mm}^{2}$. It shows that the magnet flux density in the rotor decreases with increasing current. Moreover, at $15 \mathrm{~A} / \mathrm{mm}^{2}$, the magnet flux density is under $0.8 \mathrm{~T}$ at the edge of magnet. Most of the magnet is irreversibly demagnetized at $22.5 \mathrm{~A} / \mathrm{mm}^{2}$.

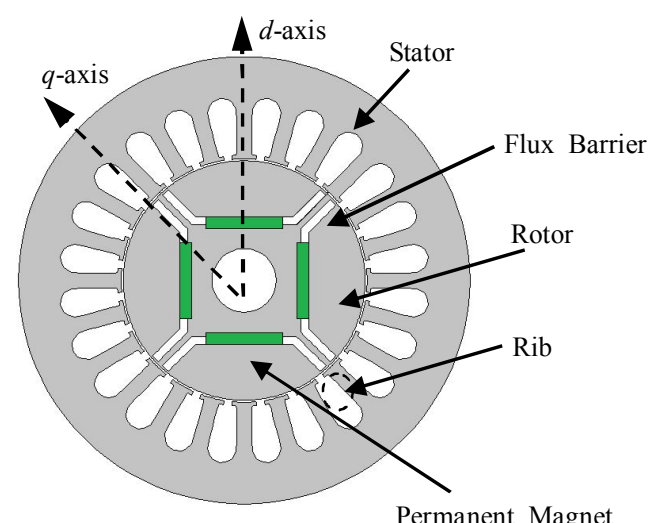

Fig. 1. Basic model

Table 1. Specifications of analysis model

\begin{tabular}{|c|c|}
\hline Item (Unit) & Value \\
\hline Stator diameter $(\mathrm{mm})$ & 112 \\
\hline Rotor diameter $(\mathrm{mm})$ & 60 \\
\hline Stack length $(\mathrm{mm})$ & 40 \\
\hline Air gap length $(\mathrm{mm})$ & 0.5 \\
\hline Rated current density $(\mathrm{A} / \mathrm{mm} 2)$ & 7.5 \\
\hline Number of turns per phase & 232 \\
\hline Winding resistance $(\Omega)\left(110^{\circ} \mathrm{C}\right)$ & 1.82 \\
\hline
\end{tabular}

\section{Rotor Structure for Improving Demagnetization}

\subsection{Effect of Using Dy-free Rare-earth Magnet in Rotor on Torque and Demagnetization Characteristics}

In this section, the effect of using a Dy-free rare-earth magnet in the rotor on the torque and demagnetization characteristics is investigated. Fig. 3 shows the rotor design of a basic model. The basic models with N52 and N32EZ as the PM material are hereafter referred to as type A and type
A', respectively. The remanences of N52 and N32EZ are respectively assumed to be 1.30 and $1.05 \mathrm{~T}$ in the $\mathrm{FE}$ analysis.

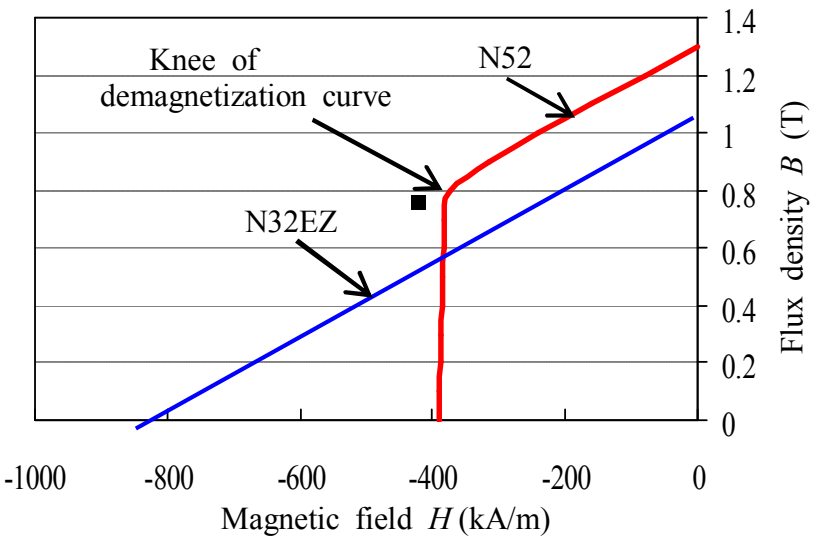

Fig. 2. Demagnetization curves for N32EZ and $\mathrm{N} 52$ at $110^{\circ} \mathrm{C}$

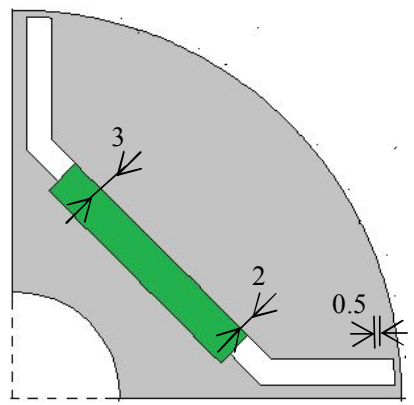

Fig. 3. Rotor structure of basic model (Type A)

Table 2 lists the analysis results at $7.5 \mathrm{~A} / \mathrm{mm}^{2}$ for types A and A'. At the base speed, type A has a higher maximum torque and output power than type A' because N52 has a higher remanence than N32EZ.

Table. 2 Comparison of Performances in Types A and A'

\begin{tabular}{|c|c|c|}
\hline Item (Unit) & Type-A & Type-A' \\
\hline Maximum Torque (Nm) & 4.542 & 4.184 \\
\hline $\begin{array}{c}\text { Current Phase at Muximum } \\
\text { Torque (deg.) }\end{array}$ & 40 & 40.5 \\
\hline Base Speed (min $\left.{ }^{-1}\right)$ & 1180 & 1184 \\
\hline Output Power at Base Speed (W) & 561.2 & 518.7 \\
\hline
\end{tabular}

Fig. 4 shows the flux density in the rotor of type A with $\mathrm{N} 52$ at 15 and $22.5 \mathrm{~A} / \mathrm{mm}^{2}$. It shows that the magnet flux density in the rotor decreases with increasing current.

Moreover, at $15 \mathrm{~A} / \mathrm{mm}^{2}$, the magnet flux density is under $0.8 \mathrm{~T}$ at the edge of magnet. Most of the magnet is irreversibly demagnetized at $22.5 \mathrm{~A} / \mathrm{mm}^{2}$.

Fig. 5 shows the demagnetization rate characteristics. It 
reveals that type $A^{\prime}$ has a demagnetization rate of $0 \%$ at $22.5 \mathrm{~A} / \mathrm{mm}^{2}$. The demagnetization rate of type $\mathrm{A}$ is about $9.13 \%$ at $15 \mathrm{~A} / \mathrm{mm}^{2}$ and about $96.9 \%$ at $22.5 \mathrm{~A} / \mathrm{mm}^{2}$. Fig. 5 shows using N52 as the PM material for the basic model causes problems with demagnetization.

incidence of irreversible demagnetization in the magnet

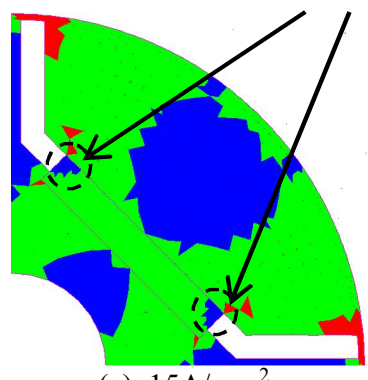

(a) $15 \mathrm{~A} / \mathrm{mm}^{2}$

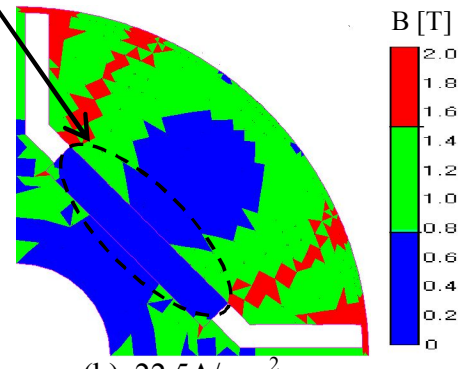

(b) $22.5 \mathrm{~A} / \mathrm{mm}^{2}$
Fig. 4. Flux density of rotor of type A using N52 ( $\beta=$ 90deg.).

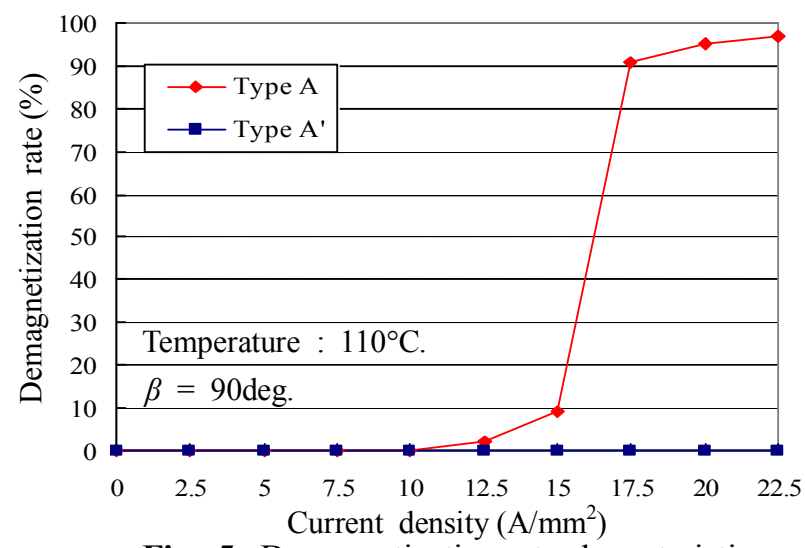

Fig. 5. Demagnetization rate characteristics

\subsection{Influence of Flux Barrier Shape on Demagnetization and Torque Characteristics}

This section considers the influence of the flux barrier shape on demagnetization. Different rotor designs are shown in Fig. 6. Each rotor structure has the same amount of magnet and uses N52. The operating temperature of the magnets is assumed to be $110^{\circ} \mathrm{C}$. As shown in Fig. 6, the flux barrier of type B is tapered, while type $\mathrm{C}$ has a larger rib than type A. Type D has a rib at the corner of the flux barrier.

Fig. 7 shows the flux from the stator without a PM at 15 $\mathrm{A} / \mathrm{mm}^{2}$. It reveals that the flux from the stator mainly flows to the rib and the flux barrier because the flux barrier is thinner than the magnet. The fluxes of types B, C, and D flow more readily through the flux barrier and the rib than type A because the flux barrier has a lower reluctance for the former types. Consequently, less flux passes through the magnet for types B, C, and D than for type A.

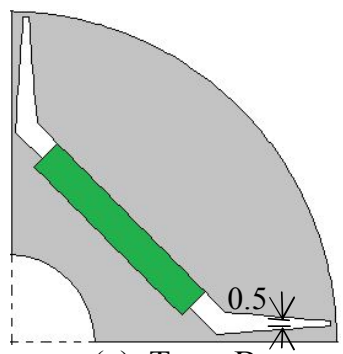

(a) Type B

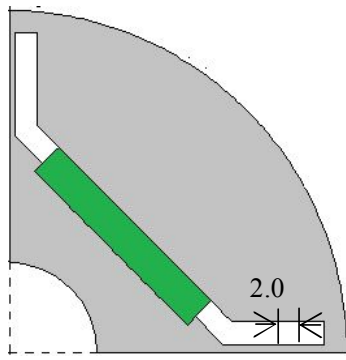

(b) Type $\mathrm{C}$

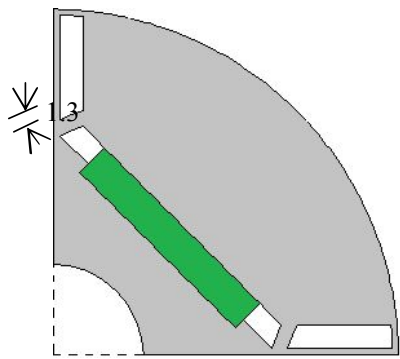

(c) Type D
Fig. 6. Rotor structures with different flux barrier shapes

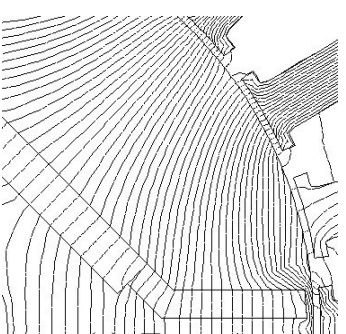

(a) Type A

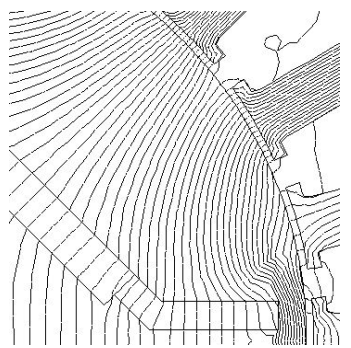

(c) Type C

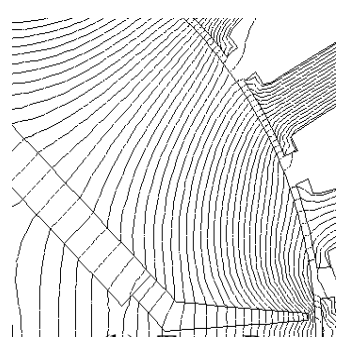

(b) Type B

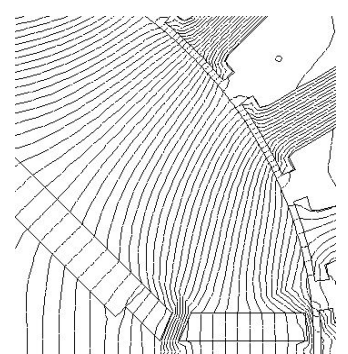

(d) Type D
Fig. 7. Flux from the stator without PM

Fig. 8 shows the demagnetization rate characteristics of types A, B, C, and D. It shows that types B, C, and D have lower demagnetization rates than type $A$. The demagnetization rate of type $\mathrm{B}$ is reduced to $3.38 \%$ at 15 $\mathrm{A} / \mathrm{mm}^{2}$. However, the demagnetization rate is about $95.1 \%$ at $22.5 \mathrm{~A} / \mathrm{mm}^{2}$, even for type B.

Fig. 9 shows the maximum torque characteristics of types A, B, C, D, and A'. Parameters at the maximum torque are listed in Table III. The current density was set to $7.5 \mathrm{~A} / \mathrm{mm}^{2}$. As shown in Fig. 9 and Table III, types B, C, and $\mathrm{D}$ have lower magnet torques than type A because the PM flux linkage $\Psi_{a}$ is lower due to increasing leakage flux. 
Type $\mathrm{C}$ has a smaller percentage of reluctance torque than types B and D because the $d$-axis inductance $L_{d}$ is high due to the small reluctance of the flux barrier.

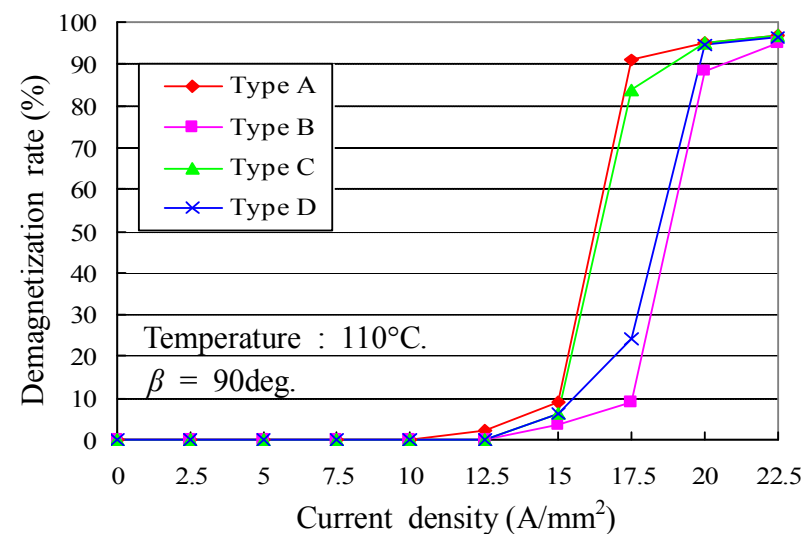

Fig. 8. Demagnetization rate characteristics

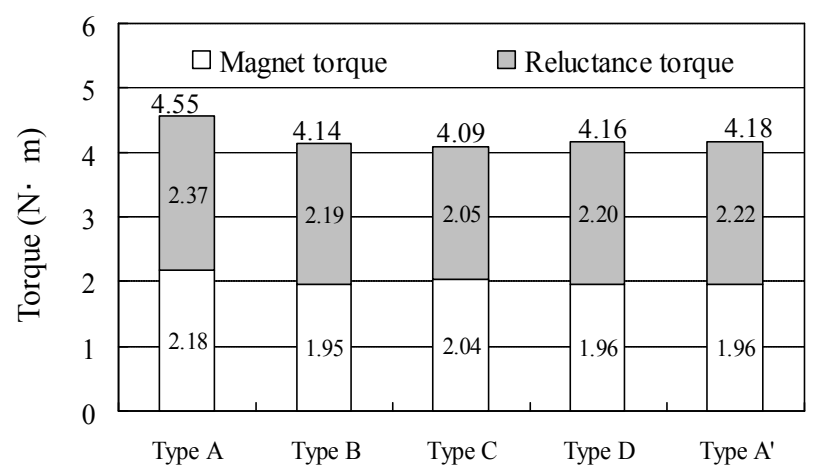

Fig. 9. Maximum torque characteristics $\left(7.5 \mathrm{~A} / \mathrm{mm}^{2}\right)$

Table 3. Parameters at Maximum Torque $\left(7.5 \mathrm{~A} / \mathrm{mm}^{2}\right)$

\begin{tabular}{|c|c|c|c|c|}
\hline & $L_{q}[\mathrm{mH}]$ & $L_{d}[\mathrm{mH}]$ & $\begin{array}{c}L_{q}-L_{d} \\
{[\mathrm{mH}]}\end{array}$ & $\Psi_{a}[\mathrm{~Wb}]$ \\
\hline Type A & 18.45 & 43.09 & 24.64 & 0.166 \\
\hline Type B & 21.28 & 46.54 & 25.26 & 0.140 \\
\hline Type C & 19.40 & 43.32 & 23.92 & 0.140 \\
\hline Type D & 19.10 & 44.73 & 25.63 & 0.137 \\
\hline
\end{tabular}

\subsection{Influence of Magnet Thickness on Demagnetization and Torque Characteristics}

This section considers the effect of the magnet thickness on demagnetization. Rotor designs are shown in Fig. 10. Each rotor structure has the same amount of the magnet and uses N52. The operating temperatures of magnets are assumed to be $110^{\circ} \mathrm{C}$. As shown in Fig. 10, types A3.5 and A4.0 have magnet thicknesses of 3.5 and $4.0 \mathrm{~mm}$ in the magnetization direction, respectively.

Fig. 11 shows the flux from the stator at $15 \mathrm{~A} / \mathrm{mm}^{2}$ without a PM. Less flux passes through the magnet for types A3.5 and A4.0 than for type A because the reluctance of the magnet is higher due to the larger magnet thickness.
Fig. 12 shows the demagnetization rate characteristics of types A, A3.5 and A4.0. It reveals that types A3.5 and A4.0 have lower demagnetization rates than type $A$. The demagnetization is suppressed with increasing the magnet thickness. The demagnetization rate of type A4.0 is reduced to $4.25 \%$ at $15 \mathrm{~A} / \mathrm{mm}^{2}$. Moreover, the demagnetization rate of type A4.0 is about $13.5 \%$ at $22.5 \mathrm{~A} / \mathrm{mm}^{2}$. These results demonstrate that increasing the magnet thickness is effective for suppressing the irreversible demagnetization.

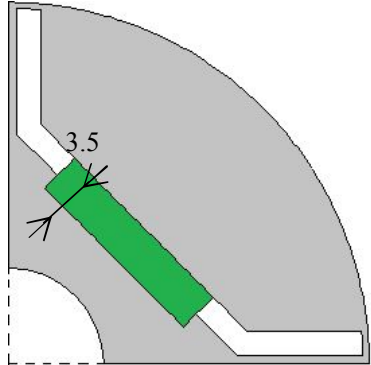

(a) Type A3.5

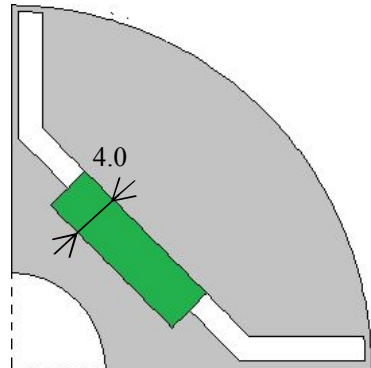

(b) Type A4.0
Fig. 10. Rotor structures with different magnet thickness

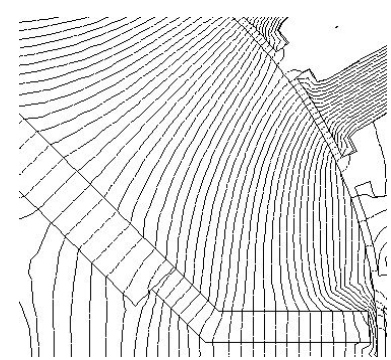

(a) Type A3.5

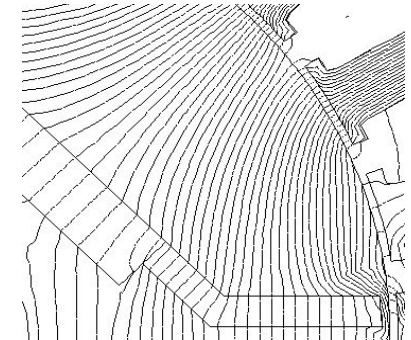

(b) Type A4.0
Fig. 11. Flux from the stator without PM

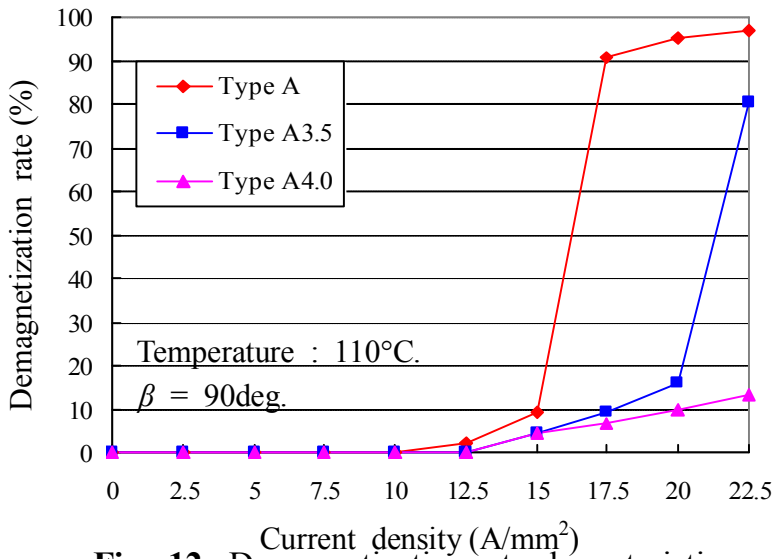

Fig. 12. Demagnetization rate characteristics

Fig. 13 shows the maximum torque characteristics of types A, A3.5, A4.0, and A'. Table IV lists the parameters at the maximum torque. The current density was set to 7.5 $\mathrm{A} / \mathrm{mm}^{2}$. As shown in Fig. 13 and Table IV, the magnet torque of types A3.5 and A4.0 is low because the PM flux linkage $\Psi_{a}$ is low due to the low magnet width while maintaining the amount of magnet. Types A3.5 and A4.0 
have higher reluctance torques than type A because $d$-axis inductance $L_{d}$ is not so much increased compared to $q$-axis inductance $L_{q}$ due to increasing thickness of the magnet.

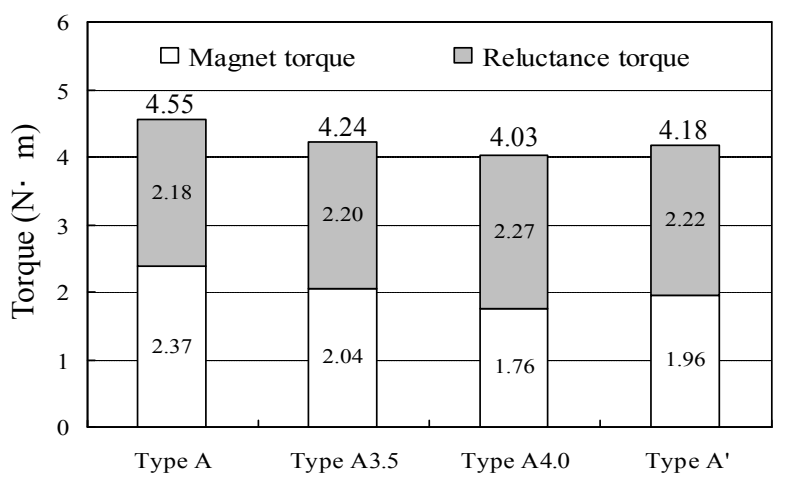

Fig. 13. Maximum torque characteristics $\left(7.5 \mathrm{~A} / \mathrm{mm}^{2}\right)$

Table 4. Parameters at Maximum Torque $\left(7.5 \mathrm{~A} / \mathrm{mm}^{2}\right)$

\begin{tabular}{|c|c|c|c|c|}
\hline & $L_{q}[\mathrm{mH}]$ & $L_{d}[\mathrm{mH}]$ & $\begin{array}{c}L_{q}-L_{d} \\
{[\mathrm{mH}]}\end{array}$ & $\Psi_{a}[\mathrm{~Wb}]$ \\
\hline Type A & 18.45 & 43.09 & 24.64 & 0.166 \\
\hline Type A3.5 & 19.06 & 44.76 & 25.70 & 0.143 \\
\hline Type A4.0 & 19.55 & 45.92 & 26.37 & 0.126 \\
\hline
\end{tabular}

This section proposes a rotor structure for suppressing the irreversible demagnetization by combining the flux barrier shape and the magnet thickness, which were examined in the previous sections. Rotor structures are shown in Fig. 14. Each rotor structure uses N52 and has the same amount of magnet whose thickness is $3.5 \mathrm{~mm}$. As shown in Fig. 14, the flux barrier of type B3.5 is tapered while type D3.5 has a rib at the corner of the flux barrier. Type E has a rib at the corner of the flux barrier and its flux barrier is slightly tapered.

Fig. 15 shows the flux from the stator without a PM at 15 $\mathrm{A} / \mathrm{mm}^{2}$. As shown in Fig. 15, less flux passes through the magnet for types B3.5, D3.5 and E than for type A because types B3.5, D3.5 and E have higher reluctance of the magnet and smaller reluctances of the flux barrier and rib.

Fig. 16 shows the demagnetization rate characteristics of types B3.5, D3.5, E, and A. It reveals that types B3.5, D3.5, and $\mathrm{E}$ have considerably lower demagnetization rates than type A. Of them, the demagnetization rate of type B3.5 is reduced to $0 \%$ at $15 \mathrm{~A} / \mathrm{mm}^{2}$. Moreover, the demagnetization rate of type B3.5 is reduced to $12.2 \%$ at $22.5 \mathrm{~A} / \mathrm{mm}^{2}$. Thus, these results demonstrate that a rotor structure that combines a tapered flux barrier and a thick magnet suppresses irreversible demagnetization.

Fig. 17 shows the maximum torque characteristics of types B3.5, D3.5, E, and A'. Table V lists the parameters at the maximum torque. The current density was set to 7.5 $\mathrm{A} / \mathrm{mm}^{2}$. As shown in Fig. 17 and Table V, types B3.5, D3.5, and $\mathrm{E}$ have nearly the same maximum torques. The maximum torque of types B3.5, D3.5, and $\mathrm{E}$ is about $6-9 \%$ lower than that of type A'.

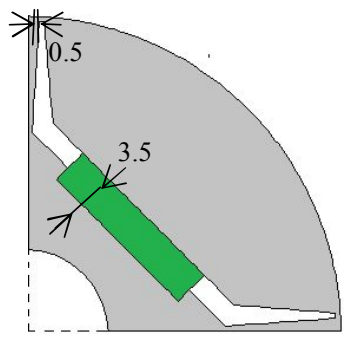

(a) Type B3.5

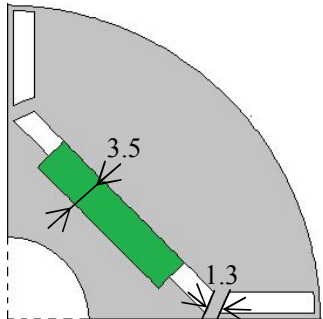

(b) Type D3.5

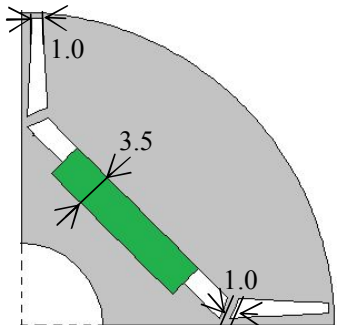

(c) Type E
Fig. 14. Rotor structures for improving demagnetization

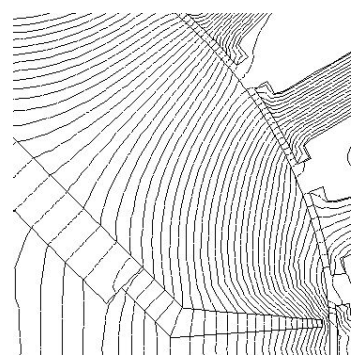

(a) Type B3.5

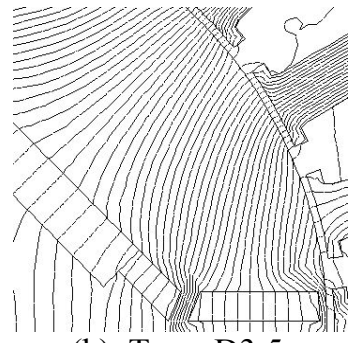

(b) Type D3.5

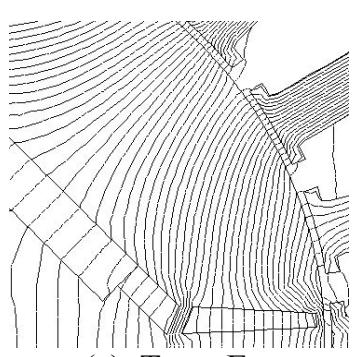

(c) Type E
Fig. 15. Flux from the stator without PM

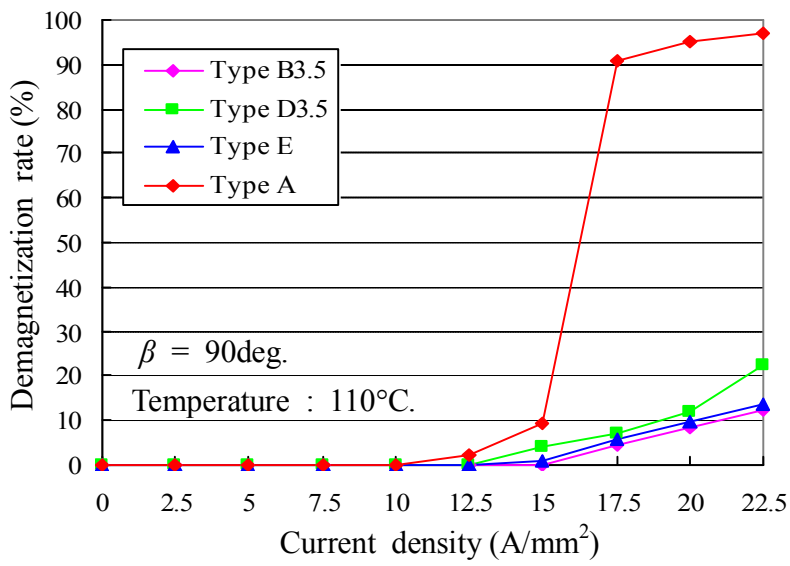

Fig. 16. Demagnetization rate characteristics 


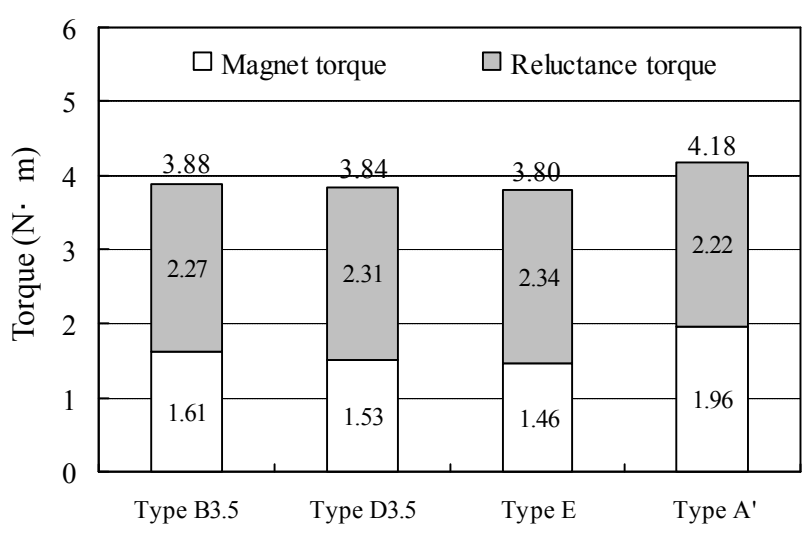

Fig. 17. Maximum torque characteristics $\left(7.5 \mathrm{~A} / \mathrm{mm}^{2}\right)$

Table 5. Parameters at Maximum Torque $\left(7.5 \mathrm{~A} / \mathrm{mm}^{2}\right)$

\begin{tabular}{|c|c|c|c|c|}
\hline & $L_{q}[\mathrm{mH}]$ & $L_{d}[\mathrm{mH}]$ & $\begin{array}{c}L_{q}-L_{d} \\
{[\mathrm{mH}]}\end{array}$ & $\Psi_{a}[\mathrm{~Wb}]$ \\
\hline Type B3.5 & 21.82 & 47.95 & 26.13 & 0.119 \\
\hline Type D3.5 & 19.72 & 46.38 & 26.66 & 0.111 \\
\hline Type E & 20.84 & 47.79 & 26.95 & 0.108 \\
\hline
\end{tabular}

\section{Performance Evaluation}

Fig. 18 shows torque versus speed curves and the output power versus speed curves for types B3.5, A4.0, and A' at $7.5 \mathrm{~A} / \mathrm{mm}^{2}$. The voltage limitation $V_{a m}$ was assumed to be $100 \mathrm{~V}$ and the current limitation $I_{a m}$ was set to $9.32 \mathrm{~A}$. As shown in Fig. 18, type B3.5 has low torque and output power about $6 \%-10 \%$ compared to type A'. Type A4.0 has low torque and output power about $3 \%-5 \%$ compared to type A'.

Fig. 19 shows the loss and efficiency characteristics. The iron loss, copper loss, and efficiency were calculated using the following equations.

$$
\begin{aligned}
& W_{i}=W_{h i}+W_{e i} \\
& W_{c}=3 R_{a} I_{e}{ }^{2} \\
& \eta=\frac{\omega T-W_{i}}{\omega T+W_{c}} \times 100
\end{aligned}
$$

where $\omega$ is the mechanical angular velocity $(\mathrm{rad} / \mathrm{s}), T$ is the torque $(\mathrm{N} \cdot \mathrm{m}), W_{i}$ is the iron loss $(\mathrm{W}), W_{h i}$ is the hysteresis loss (W), $W_{e i}$ is the eddy current loss (W), $W_{c}$ is the copper loss $(\mathrm{W}), R_{a}$ is the winding resistance $(\Omega)$, and $\eta$ is the efficiency $(\%)$. Here, the iron loss was derived by calculating the flux density (including higher orders) for one electric cycle in every element by using the 2-D FEM.

As shown in Fig. 19, the efficiencies of types B3.5 and A4.0 at $1000 \mathrm{~min}^{-1}$ under the rated current density (5.37 A) are about $1-3 \%$ lower than that of type $A^{\prime}$. In contrast, the efficiencies of types B3.5 and A4.0 at $3000 \mathrm{~min}^{-1}$ under the rated current density are about $1-3 \%$ higher than that of type A'.

Types B3.5 and A4.0 suppress the demagnetization. However, types B3.5 and A4.0 had slightly inferior motor performances to type A'. Increasing the amount of PM and the stack length of types B3.5 and A4.0 may give types B3.5 and A4.0 the same motor performance compared to type A'. This is acceptable in terms of cost because types B3.5 and A4.0 have cheaper magnets as they do not contain Dy.

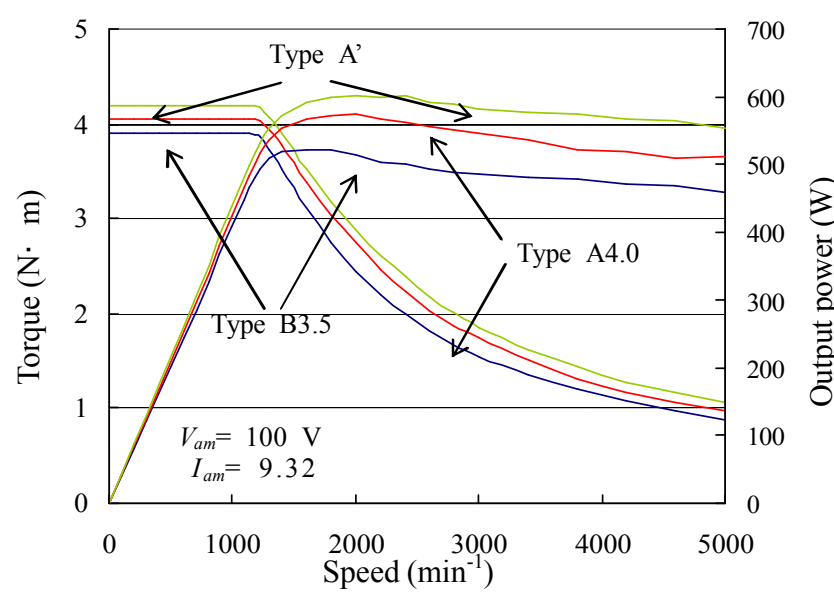

Fig. 18. Torque vs. speed and output power vs. speed $\left(7.5 \mathrm{~A} / \mathrm{mm}^{2}\right)$

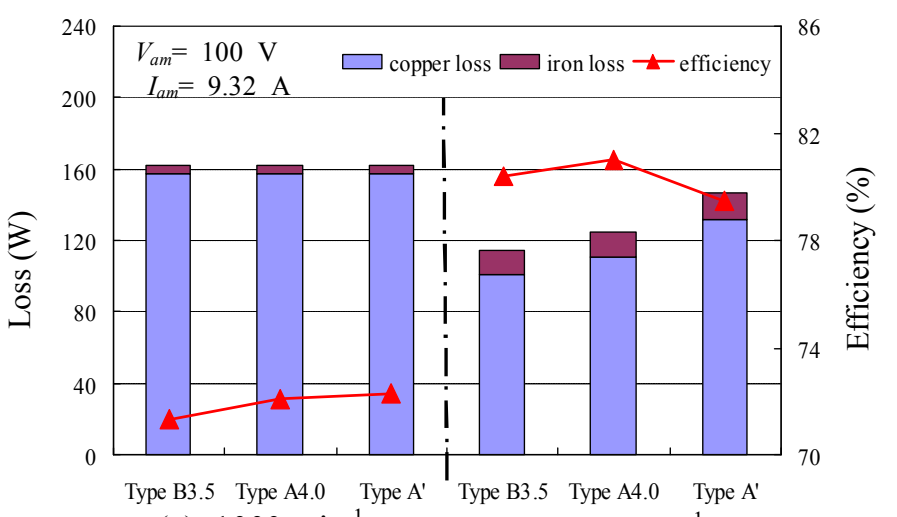

$\begin{array}{ll}\text { (a) } 1000 \mathrm{~min}^{-1} & \text { (b) } 3000 \mathrm{~min}^{-1}\end{array}$

Fig. 19. Loss and efficiency characteristics $\left(110^{\circ} \mathrm{C}\right)$

\section{Conclusion}

This study investigated flux barrier shapes and magnet thickness that suppress the irreversible demagnetization in an IPMSM with a Dy-free rare-earth magnet. The results obtained suggest that using a tapered flux barrier and a thick magnet will suppress irreversible demagnetization. However, models with a tapered flux barrier or a thick magnet had lower torques than the basic model. 
Thus, the rotor structure that combines a tapered flux barrier and a thick magnet was proposed. The proposed model has a torque and an output power that was about 6 $10 \%$ lower than the basic model that contains Dy at the rated current density. However, the proposed rotor structure with Dy-free rare-earth magnet suppressed irreversible demagnetization.

\section{References}

[1] Ki.-Chan. Kim, K. Kim and H.J. Kim, "Demagnetization Analysis of Permanent Magnets According to Rotor Types of Interior Permanent Magnet Synchronous Motor" IEEE Trans. Mag. , Vol. 45, no. 6, pp. 2799-2802, 2009.

[2] K. Murata, M. Sanada, S. Morimoto and Y. Takeda, "Torque Performance and Magnet Arrangement for IPMSM Considering Demagnetizing Ability", Proc. of ICEMS2006, DS1F1-10, 2006.

[3] T. Tokuda, M. Sanada and S. Morimoto, "Influence of Rotor Structure on Performance of Permanent Magnet Assisted Synchronous Reluctance Motor", Proc. of ICEMS2009, DS2G1-3, 2009.

[4] Abdul Rehman Tariq, Carlos E. Nino-Baron and Elias G. Strangas, "Overload Considerations for Design and Operation of IPMSMs" IEEE Trans. Ener. Conv. , Vol. 25, no. 4, pp. 921-930, 2010.

[5] Chang-Sung Jin, Dae-Sung Jung, Ki-Chan Kim, Yon-Do Chun, Hyung-Woo Lee and Ju Lee, "A Study on Improvement Magnetic Torque Characteristics of IPMSM for Direct Drive Washing Machine" IEEE Trans. Mag. , Vol. 45, no. 6, pp. 2811-2814, 2009.

[6] Liang Fang, Sung-Il Kim, Soon-O. Kwon and Jung-Pyo Hong, "Novel Double-Barrier Rotor Designs in Interior-PM Motor for Reducing Torque Pulsation" IEEE Trans. Mag. , Vol. 46, no. 6, pp. 2183-2186, 2010.

[7] Chao-hui Zhao, Hai-hong Qin and Yang-guang Yan, "The optimization of rare earth magnet thickness of IPM synchronous machine with flux concentration function" IEEE Trans. Mag. , Vol. 44, no. 11, pp. 185-190, 2005.

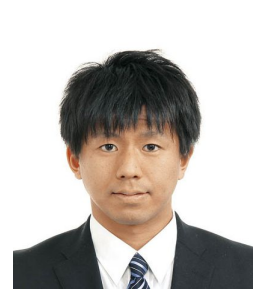

Keigo Imamura received B.E degree from Osaka Prefecture University, Sakai, Japan, in 2012 where he is currently working toward the M.E. degree in the Graduate School of Engineering. His research interests are electrical machines, in particular, permanentmagnet synchronous motors.

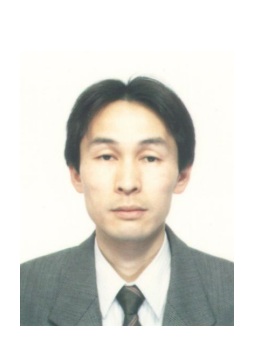

Masayuki Sanada received the B.E., M.E., and Ph.D. degrees from Osaka Prefecture University, Sakai, Japan, in 1989, 1991, and 1994, respectively. Since 1994, he has been with the Graduate School of Engineering, Osaka Prefecture University, where he is currently an Associate Professor. His main areas of research interest are linear motors for direct-drive applications, their control systems, and magnetic field analysis. Dr. Sanada is a member of the Institute of Electrical Engineers of Japan, the Japan Institute of Power Electronics, and the Japan Society of Applied Electromagnetics and Mechanics.

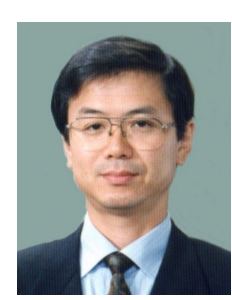

Shigeo Morimoto received the B.E., M.E., and Ph.D. degrees from Osaka Prefecture University, Sakai, Japan, in 1982, 1984, and 1990, respectively. He joined Mitsubishi Electric Corporation, Tokyo, Japan, in 1984. Since 1988, he has been with the Graduate School of Engineering, Osaka Prefecture University, where he is currently a Professor. His main areas of research interest are permanent magnet synchronous machines, reluctance machines, and their control systems. Dr. Morimoto is a member of the Institute of Electrical Engineers of Japan, the Society of Instrument and Control Engineers of Japan, the Institute of Systems, Control and Information Engineers, and the Japan Institute of Power Electronics.

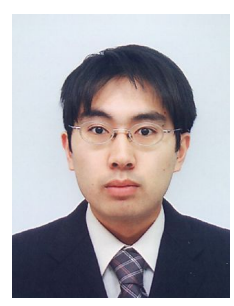

Yukinori Inoue received the B.E. and M.E. and Ph.D. degrees from Osaka Prefecture University, Sakai, Japan, in 2005, 2007 and 2009, respectively, where he is currently working toward the Ph.D. degree in the Graduate School of Engineering. His research interests include control of electrical drives, in particular, the direct torque control of permanent-magnet synchronous motors and position-sensorless control of these motors. 